\title{
El régimen desequilibrado del incumplimiento en los contratos del Estado ${ }^{(*)}$
}

Ramón Alberto Huapaya Tapia

Abogado por la Universidad de Lima.

Magíster en Regulación por la Universidad Peruana de Ciencias Aplicadas. Profesor Ordinario de Derecho Administrativo en la Pontificia Universidad Católica del Perú. Miembro del Grupo de Investigación en Derecho Administrativo — GIDA—.

Oscar Alejos Guzmán

Abogado por la Universidad Nacional Mayor de San Marcos.

(*) Las opiniones vertidas en el presente artículo reflejan nuestra opinión personal y no comprometen a las instituciones a las cuales pertenecemos.

SUMARIO:

I. Introducción.

II. El incumplimiento de la entidad.

III. El incumplimiento del contratista.

1. Cualquier incumplimiento habilita la resolución.

2. Régimen de penalidades.

3. Ejecución de garantía de fiel cumplimiento.

4. Sanción de inhabilitación.

IV. El desequilibrio y su falta de justificación.

V. Más allá de la reforma: cómo cambiar las cosas sin cambiar la ley.

VI. Reflexiones conclusivas. 


\title{
RESUMEN:
}

Los contratos se celebran para cumplirse. De ello se deriva que el incumplimiento es siempre una situación irregular e indeseada. Siendo así, la ley garantiza diversas medidas de protección frente al incumplimiento, tanto en contratos privados como públicos. En este último caso, en la medida que el incumplimiento puede provenir del contratista o del Estado, la ley los protege a ambos. Sin embargo, la regulación peruana no establece las mismas consecuencias por el incumplimiento, de manera que existen consecuencias más gravosas si quien incumple es el contratista. El presente artículo busca explicar dicha diferenciación, mediante un análisis crítico.

Palabras clave: Contrato público, incumplimiento contractual, resolución de contrato, igualdad, penalidades.

\begin{abstract}
:
Contracts are celebrated to be complied with. Therefore, breaches of contract are always an irregular and undesirable situation. That being the case, the law guarantees several protection measures against non-compliance, both in private and in public contracts. In the latter case, since the breach can come from either the contractor or the State, the law protects them both. However, Peruvian regulations do not establish the same consequences for the same occurrence, and as a result there are more burdensome consequences if the party which incurred in non-compliance was the contractor. This article seeks to explain that differentiation, through a critical analysis.

Keywords: public contract, breach of contract, contract resolution, equality, penalties.
\end{abstract}

\section{INTRODUCCIÓN}

En cualquier contrato, privado o público, el incumplimiento constituye una situación indeseable. Por eso la ley apareja consecuencias negativas para la parte que incumple. La principal consecuencia negativa es la posibilidad de resolver el contrato. De esta forma, la ley busca satisfacer el interés del acreedor y desincentivar el incumplimiento.

Situación similar la encontramos en el régimen de los contratos públicos. En este artículo, nos centraremos específicamente en las llamadas compras públicas', reguladas en el Perú por la Ley de Contrataciones del Estado y su Reglamento ${ }^{2}$ - en adelante la "Ley" y el "Reglamento" respectivamente-. Como veremos más adelante, estas normas contemplan también consecuencias gravosas para quien incumple.
Sin embargo, las consecuencias que prevé la norma son marcadamente diferentes dependiendo de quién incumple. Así, quien se ve más perjudicado en este régimen desequilibrado es el contratista. Mientras el incumplimiento que, además, debe ser de una obligación esencial- de la entidad solo acarrea la posibilidad de resolución y eventualmente una indemnización; el incumplimiento del contratista - de cualquier obligación - acarrea penalidades, posibilidad de resolución del contrato, ejecución de garantía de fiel cumplimiento, posible indemnización, y denuncia ante el Tribunal de Contrataciones del Estado para que se imponga una sanción de inhabilitación.

Esta desigualdad de trato se sustentaría en el interés público que está detrás del contrato y que se ve afectado cuando el contratista incumple. Sin embargo, aun asumiendo dicha

1. Las compras públicas o "marchés publics" son una especie del género de los contratos públicos en nuestro ordenamiento jurídico. Sobre el concepto y clasificación de los contratos públicos en nuestro ordenamiento jurídico, puede verse: Víctor Baca, "Concepto, clasificación y regulación de los contratos públicos en el Derecho peruano", Ius et Veritas 48 (2014): 270-297; y, Ramón Huapaya, “Concepto, especies y criterios del contrato público”, en Estudios de Derecho Administrativo. El Derecho Administrativo Iberoamericano. Innovación y reforma. Libro Homenaje al Profesor Juan Carlos Cassagne, ed. por Juan Carlos Morón Urbina y Jorge Danós Ordóñez, (Lima: Gaceta Jurídica, 2018), 617-627.

2. Haremos referencia al Texto Único Ordenado de la Ley de Contrataciones del Estado, aprobado por Decreto Supremo Nº82-2019-EF; y a su Reglamento, aprobado por Decreto Supremo N 344-2018-EF. 
premisa como cierta, es imposible no preguntarse si se justifica dicho trato diferenciado. Si fuera positiva la respuesta, ¿se justifica que la diferenciación sea tan acentuada?

En el presente artículo demostraremos que no existe justificación válida para dicho trato diferenciado. Para ello, describiremos los absurdos a los que nos lleva la normativa actual, los mismos que suelen degenerar en claros excesos punitivos que no sólo afectan al contratista, sino también al mismo interés público que supuestamente se busca proteger.

\section{EL INCUMPLIMIENTO DE LA ENTIDAD}

Como es común en cualquier sistema legal moderno, las partes de un contrato pueden resolverlo si una de ellas incumple con sus obligaciones. Lo mismo sucede en los contratos públicos, de manera que tanto el contratista como la entidad pueden resolver el contrato ante un incumplimiento.

Sin embargo, no todo incumplimiento debería permitir la resolución. Pensemos en incumplimientos menores, como el atraso en el pago por un día o la entrega de un informe que tiene observaciones subsanables. En dichos casos, la resolución puede considerarse como un remedio extremo que terminaría siendo ineficiente.

En efecto, imaginemos un escenario en el que se permitiera resolver los contratos por cualquier incumplimiento. Si fuera así, las partes tomarían precauciones muy costosas para evitar incumplir. Estos costos podrían llegar a ser muy elevados, volviendo toda la operación económica ineficiente.

En el caso de los contratos públicos, el problema puede ser mayor. En efecto, es posible que los contratistas no solo decidan tomar precauciones muy costosas para evitar incumplir, sino que ni siquiera participen en los procesos de selección. El razonamiento es simple: si la ejecución de un contrato con el Estado va a ser muy costosa, muchos postores optarán por no firmar esos contratos. ¿El resultado? Procesos de selección menos competitivos, menos postores y menos chances de satisfacer adecuada- ADMINISTRATIVO mente los intereses del Estado.

Por ello, la resolución, como remedio contractual, debería estar reservada a incumplimientos de gravedad. Esta exigencia es mayor en los contratos públicos, porque aquí está en juego el interés público que precisamente se satisface con la ejecución del contrato, no con su terminación. Al Estado le interesa que el contrato se ejecute y no que se resuelva por cualquier incumplimiento. $^{3}$

En esa línea es que la norma peruana establece que el contratista solo puede resolver el contrato si la entidad incumple una obligación esencial. Solo si la entidad incumple una obligación esencial, el contratista queda legitimado para resolver, previa intimación.

Ahora bien, ¿qué es una obligación esencial? O, mejor dicho, ¿qué obligaciones son esenciales? La Ley calla al respecto, por lo que cabe buscar alguna respuesta a nivel de la doctrina. Juan Carlos Morón y Zita Aguilera ${ }^{4}$ mencionan como ejemplo la falta de entrega de terrenos y el incumplimiento de pago. Según estos autores, una obligación esencial sería aquella indispensable para lograr la finalidad del contrato. Los ejemplos brindados tienen perfecto sentido. Si el Estado no cumple con entregar el terreno, es físicamente imposible para el contratista cumplir con su prestación. Lo mismo sucede si el pago no se realiza, pues el interés del contratista se ve perjudicado, quedando legitimado para resolver.

Una posición similar la tiene el Organismo Su-

3. Libardo Rodríguez, "Los efectos del incumplimiento de los contratos administrativos", AÍDA. Ópera Prima de Derecho Administrativo 5 (2009): 355.

4. Juan Carlos Morón y Zita Aguilera, Aspectos jurídicos de la contratación estatal, (Lima: PUCP, 2017), 158. 
pervisor de las Contrataciones del Estado OSCE. Por ejemplo, en la Opinión N 190-2015/ DTN, la Dirección Técnico Normativa del OSCE señaló lo siguiente: "(...) una obligación esencial es aquella cuyo cumplimiento resulta indispensable para alcanzar la finalidad del contrato $y$, en esa medida, satisfacer el interés de la contraparte; estableciéndose como condición adicional para tal calificación que se haya contemplado en las Bases o en el contrato".

Coincidimos en que una obligación esencial solo puede ser aquella que resulte indispensable para que se cumpla la finalidad del contrato, con plena satisfacción de los intereses de las partes. Sin embargo, no consideramos que sea imprescindible que exista una previsión expresa en las bases o en el contrato; la esencialidad proviene de la naturaleza misma de la operación económica, con prescindencia de su previsión en un documento.

Además, no puede perderse de vista que la entidad predispone el contenido de las bases y el contrato, con injerencia mínima por parte del contratista. Siendo así, no es razonable que solo se consideren como obligaciones esenciales las previstas expresamente en dichos documentos, pues se estaría admitiendo que solo son esenciales las obligaciones que la entidad considere como tales. De ahí que, reiteramos, las obligaciones esenciales se reconocen por su naturaleza indispensable para la finalidad del contrato.

Sin perjuicio de ello, no negamos que una forma de reducir la incertidumbre es la previsión de las obligaciones esenciales en los documentos que forman el contrato - contrato, bases, etc.- Caso contrario, queda en cabeza del contratista dilucidar si una obligación es esen- cial, a fin de optar o no por la resolución; opción que siempre podrá ser controvertida por la entidad y eventualmente esclarecida por los árbitros en el correspondiente proceso. ${ }^{5}$

Finalmente, consideramos importante mencionar a la llamada carga de colaboración que pesa sobre el deudor en un contrato. Dicha carga es particularmente relevante en los contratos públicos, dado que el contratista asume una obligación - de dar o hacer- que, en muchos casos, no puede ser cumplida sin la colaboración de la entidad -en la entrega de ambientes, en la facilitación de los terrenos, en la entrega de información de sustento, etcétera-. Surge entonces la interrogante: ¿es la carga de colaboración una obligación esencial?

La distinción entre obligaciones y cargas en la teoría del derecho sugiere una respuesta negativa. Sin embargo, creemos que es necesario apartarnos de dicha disquisición teórica y partir de la función de la carga de colaboración. Esta carga - en cabeza del Estado- es indispensable para el cumplimiento del contrato ${ }^{6}$; de ahí que deba interpretarse que, cuando el Reglamento habla de obligaciones esenciales, debe entenderse incluidas no sólo las obligaciones en sentido estricto, sino también las cargas que son indispensables para alcanzar la finalidad del contrato. ${ }^{7}$

\section{EL INCUMPLIMIENTO DEL CONTRATISTA}

\section{Cualquier incumplimiento habilita la re- solución.}

Conforme a la exposición anterior, estamos de acuerdo en que la resolución, como remedio frente al incumplimiento contractual, sólo debería operar ante el incumplimiento de obliga-

5. Ricardo Rodríguez Ardiles, “Resolución de contrato por incumplimiento de obligación esencial no pactada en los contratos sujetos a la ley de contrataciones del Estado", Arbitraje PUCP 1 (2011): 47.

6. Luciano Barchi, "Mora del acreedor y resolución del contrato por incumplimiento de la carga de colaboración", ADVOCATUS 12, (2005): 179.

7. Ibid. 
ciones esenciales. Por ello, nos parece correcta la precisión que realiza el Reglamento y que, en cierto modo, restringe al contratista la posibilidad de resolver.

El problema está en que al contratista no le aplica - al menos eso nos sugiere una lectura literal del Reglamento - la misma regla. Así, al referirse al incumplimiento del contratista que habilita la resolución, el Reglamento no habla de obligaciones esenciales, sino de obligaciones a secas.

A partir de dicho dato, la doctrina ha interpretado que existe un tratamiento diferenciado. Mientras el contratista solo puede resolver por incumplimiento de obligaciones esenciales por parte de la entidad, ésta puede resolver por cualquier incumplimiento del contratista.

Si bien se reconoce esta situación desigual, no se ahonda mucho en las explicaciones. ${ }^{8}$ Juan Carlos Morón y Zita Aguilera ${ }^{9}$ sostienen que

"ningún contratista postula y se embarca en un contrato con el Estado para resolverlo inmediatamente, pues adquieren demasiadas obligaciones con personal, proveedores y financistas. Por ello esta facultad requiere como presupuesto encontrarnos ante una obligación esencial a cargo de la entidad que esta sea pasible de incumplirse".

Discrepamos de dicha justificación. Es cierto que los contratistas no desean resolver el contrato por la inversión que han realizado para resultar adjudicatarios, pero ello explicaría su conducta, mas no la limitación legal que venimos comentando. Resulta además un contrasentido que se limite al contratista su facultad de resolver para protegerle. Sencillamente no tiene sentido.

El límite a la facultad de resolver del contratista no puede justificarse en el mismo contratista; a menos que pensemos que el legislador quiere tutelar al contratista de sus propios errores, en una lógica paternalista que resulta inaceptable. Por ello, la justificación ha de encontrarse en la tutela de la propia entidad.

El tema es que cualquier justificación que bus- ADMINISTRATIVO que beneficiar a la entidad, en realidad debería beneficiar al interés público; sin embargo, no vemos que exista ningún interés público en permitir que la entidad resuelva por cualquier motivo. Por el contrario, dicha posibilidad abre la puerta a decisiones ineficientes y contrarias al interés público.

Evidentemente esta regla es ineficiente. Se condena al contratista a tomar precauciones excesivas para no incumplir, dado que cualquier incumplimiento - aun cuando sea parcial o responda a una obligación no esencial- habilita a la entidad a resolver el contrato, con todas las consecuencias que acarrea. Como hemos señalado previamente, estos costos excesivos pueden terminar desincentivando incluso la participación de postores en los procesos de selección.

Pero no sólo ello, sino que se termina por afectar al propio interés público subyacente al contrato. En efecto, hemos visto anteriormente que el interés público demanda que los contratos se ejecuten y cumplan a cabalidad, por lo que se restringe la opción de darlo por terminado. Evidentemente ello aplica para ambas partes; es más, la entidad debería tener más limitada la opción de resolver, porque es ella la primera interesada en que el contrato se ejecute y el interés público se vea satisfecho. De ahí que carezca totalmente de sentido permitir que la entidad resuelva el contrato por cualquier incumplimiento.

\section{Régimen de penalidades.}

Claro está que la entidad no está compelida

8. Rodríguez Ardiles "Resolución de contrato por incumplimiento de obligación esencial no pactada en los contratos sujetos a la ley de contrataciones del Estado", 41

9. Morón y Aguilera, Aspectos jurídicos de la contratación estatal, 162. 
a resolver. Puede no hacerlo. Es más, la Ley le otorga otro mecanismo para incentivar el cumplimiento: la imposición de penalidades. En ese sentido, la entidad tiene dos armas para enfrentar el incumplimiento: las penalidades y la resolución.

Esto de por sí la coloca en una situación de ventaja. El contratista no puede aplicar penalidades ante el incumplimiento de la entidad. $Y$, cuando quiere resolver, debe demostrar que el incumplimiento responde a una obligación esencial. La entidad, en cambio, tiene un arsenal de medidas.

Incluso en el tema de penalidades, la entidad posee muchas ventajas. La Ley contempla dos tipos de penalidades: una tasada, conforme a supuestos concretos que se plasman en el contrato; la otra, conforme a una fórmula que se calcula en base a los días de retraso en el cumplimiento.

La penalidad tasada permite a la entidad penalizar cualquier incumplimiento del contratista, con tal que lo plasme expresamente en el contrato. En la medida que la entidad predispone el contenido del contrato, teniendo el contratista mínima injerencia en el mismo ${ }^{10}$, es evidente que estamos frente a un poder que se presta para el abuso. Ello, pese a que los artículos 161 y 163 del Reglamento disponen que las penalidades tienen que ser objetivas, razonables, congruentes y proporcionales.

Sin duda alguna, las normas citadas son bastante positivas. La exigencia de objetividad, razonabilidad y congruencia es importante, en la medida que fija un límite al poder discrecional de fijar penalidades que tendría la entidad. Sin embargo, pese a ello, se mantiene la posibilidad de abuso de dicha discrecionalidad. A las pruebas nos remitimos. Veamos unos ejemplos del contrato $N^{\circ} 162-2016-S E D A P A L$, suscrito para el servicio de mantenimiento de los sistemas de agua potable y alcantarillado. En este contrato, se fijan - entre otros - los siguientes supuestos de penalidad:

"Por no entregar en la fecha establecida a sus trabajadores, el fotocheck (...)".

"Por no portar el fotocheck en todo momento de ejecución de la subactividad y en el lugar indicado (...)".

"Cuando no informa mensualmente el pago de los haberes, contratos de trabajo, las planillas de pago de su personal profesional, administrativo y operarios".

"Por no cumplir, injustificadamente con el pago de haberes $y / 0$ beneficios a sus trabajadores (...)".

Los supuestos citados demuestran una falta de razonabilidad y congruencia con el objeto del contrato. Falta de razonabilidad porque se trata -en los dos primeros casos- de conductas menores que no ponen en riesgo la finalidad del contrato, además que se pueden implementar medidas menos gravosas para corregir la conducta del contratista - una amonestación o llamada de atención parecerían suficientes-.

Por su parte, en los dos últimos casos se aprecia una falta de congruencia, dado que no existe relación entre dichas conductas penalizables y el objeto del contrato; es más, llama bastante la atención que la entidad no solo pretenda fiscalizar el cumplimiento de obligaciones laborales, sino que además regula un supuesto deber de información sobre el cumplimiento de dichas obligaciones. Se trata, a nuestro parecer, de un exceso en la imposición de obligaciones y, por ende, un exceso en la fijación de penalidades.

Se aprecia así que, aun cuando la norma exija razonabilidad, objetividad y congruencia, las entidades muchas veces pueden estipular penalidades que no cumplen con esos crite-

10. Oscar Alejos, “Convenios arbitrales desequilibrados en los contratos públicos bajo la Ley de Contrataciones del Estado", Derecho PUCP 28, (2019): 358-359. 
rios. Frente a ello, es importante recordar que la discrecionalidad que les concede la norma para fijar penalidades no puede ser confundida con arbitrariedad. En efecto, es cierto que las entidades pueden fijar discrecionalmente los supuestos penalizables; sin embargo, esa fijación debe responder a criterios de objetividad, razonabilidad y congruencia. Caso contrario, estaríamos frente a penalidades ilegalmente estipuladas $y$, eventualmente, indebidamente impuestas.

Por otro lado, es importante mencionar que, en ambos tipos de penalidad, tanto la penalidad por retraso como la penalidad tasada tienen como límite el $10 \%$ del valor del contrato, supuesto en el cual la entidad queda habilitada para resolver el contrato sin intimación. He aquí otra prueba del desbalance que existe entre contratista y entidad, pues el primero nunca puede resolver el contrato sin previa intimación, por más grave que sea el incumplimiento.

Un aspecto de especial importancia es el procedimiento de imposición de la penalidad por mora. A falta de un procedimiento expreso en la Ley o el Reglamento, se ha vuelto - malacostumbre de las entidades imponer las penalidades sin previo aviso. Así, el contratista se entera una vez que se liquida o se paga, descontando los montos de penalidades por mora.

Esta práctica debe descartarse. En primer lugar, porque todo acto de gravamen -incluyendo las penalidades-debe venir precedido de una audiencia previa.." En segundo lugar, porque el mismo Reglamento permite al contratista liberarse de la penalidad por mora si demuestra que el retraso no le es imputable; para ello, de- bería ser previamente informado antes de que se le imponga la penalidad.

Así, un punto a favor del marco normativo actual es que se ha eliminado la dependencia que existía entre la penalidad por mora y la ampliación de plazo — artículo 162 del Reglamento-. ADMINISTRATIVo Antes, si uno no pedía una ampliación de plazo, o le era denegada, el retraso se consideraba penalizable. A la fecha, ello no es así, de manera que el contratista - con o sin ampliación de plazo - tiene la posibilidad de demostrar que el retraso no le resulta imputable $y$, por ende, no puede ser penalizado. ${ }^{12}$

Quizás siguiendo esta misma lógica, las reglas deberían dirigirse a controlar mejor la estipulación y ejecución de las penalidades, dado que estas son el mecanismo más natural y propio para desincentivar incumplimientos contractuales. Iñigo Sanz ${ }^{13}$ privilegia el uso de penalidades contractuales, precisamente porque las considera más eficaces como medidas coercitivas e indemnizatorias. Compartimos su apreciación.

\section{Ejecución de garantía de fiel cumpli- miento.}

Ahora bien, como adelantábamos al inicio de este artículo, la resolución del contrato imputable al contratista acarrea consecuencias dramáticas para éste: la ejecución de la garantía de fiel cumplimiento -equivalente al $10 \%$ del monto del contrato- y la denuncia ante el Tribunal de Contrataciones del Estado para que se le sancione con una inhabilitación para contratar. En ambos casos, el contratista se ve sometido a procesos kafkianos, en tanto no importan los argumentos que exponga, igual su destino está decidido de antemano.

11. Î́nigo Sanz, "Propuesta para una mejora del régimen sancionador en materia de contratos públicos" en Tendencias actuales en contratación pública, dirigido por Eloy Espinosa-Saldaña, (Lima: Gaceta Jurídica, 2014), 139.

12. Víctor Baca, "La modificación del régimen jurídico de los contratos de gestión patrimonial en derecho peruano", Derecho Administrativo: Hacia un Estado más confiable. Libro de ponencias del VII Congreso Nacional de Derecho Administrativo, (Lima: ECB, 2016), 547.

13. Sanz, "Propuesta para una mejora del régimen sancionador en materia de contratos público", 139. 
La garantía de fiel cumplimiento se ejecuta de inmediato, sin que el contratista pueda argüir nada en su defensa. Además, se ejecuta por el íntegro, sin que sea necesario demostrar que el daño sufrido es proporcional al monto ejecutado, pese a que éste cumple una función resarcitoria. Textualmente, el artículo 155 del Reglamento establece que el monto de la garantía le corresponde a la entidad "independientemente de la cuantificación del daño efectivamente irrogado".

Aun cuando la Ley no lo diga, la interpretación que ha realizado el OSCE es que dicha garantía no solo cumpliría una función resarcitoria, sino además compulsoria. Por ejemplo, en la Opinión Nº 017-2019/DTN, se señaló lo siguiente:

"En adición a ello, este Organismo Técnico Especializado ha señalado en diversas Opiniones que tales garantías cumplían una doble función: compulsiva y resarcitoria. Eran compulsivas, puesto que pretendían compeler $u$ obligar al contratista a cumplir con todas sus obligaciones contractuales, bajo apercibimiento de ejecutar las garantías presentadas por este; asimismo, eran resarcitorias, puesto que pretendían, con su ejecución, indemnizar a la Entidad por los eventuales daños que hubiera sufrido debido al incumplimiento del contratista".

Entonces, al ejecutar dicha garantía, la entidad no sólo buscaría resarcir los daños generados por el incumplimiento, sino además "compeler" al contratista para que cumpla.

Esta doble función revela lo que podría ser un exceso de punición, porque el mismo Reglamento establece que la entidad podría reclamar un resarcimiento mayor, si la garantía no cubre los daños. En efecto, el artículo 166 del Reglamento dispone expresamente que la entidad "ejecuta las garantías que el contratista hu- biera otorgado sin perjuicio de la indemnización por los mayores daños irrogados".

Entonces, el escenario ventajoso para la entidad es evidente. Si el daño sufrido es menor al monto de la garantía, igual se ejecuta toda sin devolución, porque la diferencia se considera un mecanismo de compulsión; si el daño sufrido es mayor al monto de la garantía, la entidad ejecuta por el todo y, además, puede reclamar mayores daños en arbitraje. Algo anda mal aquí.

Esta regla de ejecutar la garantía por el todo, aun cuando el daño sea menor, es totalmente irrazonable. La supuesta función punitiva de la garantía carece de justificación, más aún cuando el incumplimiento ya tiene sanción, como veremos en breve.

\section{Sanción de inhabilitación.}

Finalmente, la denuncia ante el Tribunal de Contrataciones del Estado constituye la antesala de un procedimiento sancionador que de todas maneras se iniciará. ${ }^{14} \mathrm{Y}$, una vez iniciado, tiene un cauce que podría calificarse de automático. En efecto, en este procedimiento, el Tribunal valora dos escenarios: (i) si el contratista ha dejado consentir la resolución, se presume que era culpable $y$, por ende, se le sanciona sin importar su defensa - sólo se verifica que se haya seguido el proceso previo de resolución vía intimación-; o, (ii) si el contratista ha controvertido la resolución ante tribunal arbitral, se espera la decisión de éste: si confirma la resolución, se sanciona; caso contrario, se archiva.

Como se puede apreciar, el procedimiento sancionador se torna casi en automático. La evaluación que realiza el Tribunal es prácticamente nula, limitándose a comprobar los supuestos antes mencionados. Cabe señalar que esta interpretación la tiene el Tribunal desde la nor-

14. Cabe mencionar que la infracción se encuentra tipificada en el artículo 50 de la Ley, en los siguientes términos: "Ocasionar que la Entidad resuelva el contrato, incluido Acuerdos Marco, siempre que dicha resolución haya quedado consentida o firme en vía conciliatoria o arbitral". 
mativa anterior; tan es así que en el año 2012 tomó el Acuerdo Nº06/2012:

"En el procedimiento sancionador no corresponde evaluar la decisión de la Entidad de resolver el contrato, constituyendo un elemento necesario para imponer la sanción, verificar que esa decisión ha quedado consentida, por no haberse iniciado los procedimientos de solución de controversia conforme a lo previsto en la Ley y su Reglamento. De haberse iniciado una conciliación o un procedimiento arbitral, un requisito para la imposición de la sanción es que haya un acta de conciliación o un laudo arbitral que confirme la resolución contractual declarada por la Entidad o, en caso contrario, un acta o constancia emitida por el conciliador en el que conste que no hubo acuerdo sobre esta decisión o una resolución que declare el archivamiento definitivo del proceso arbitral".

El Tribunal mantiene la misma interpretación a la fecha. Por ejemplo, en la Resolución $\mathrm{N}^{\circ}$ 0505-2019-TCE-S1, se señaló lo siguiente:

"Por otro lado, a fin de verificar si la decisión de resolver el contrato fue consentida o se encuentra firme, como segunda condición para determinar responsabilidad administrativa, es pertinente indicar que, en los procedimientos administrativos sancionadores referidos a la infracción materia de análisis, lo que corresponde es verificar si las partes han recurrido oportunamente a los mecanismos de solución de controversias, es decir a conciliación o arbitraje, a fin de verificar la conformidad sobre la decisión de la Entidad de resolver el contrato.

Para ello, deberá analizarse los plazos y el procedimiento de solución de controver- sias contractuales aplicable a cada caso en concreto. Si se comprueba que se iniciaron oportunamente los mecanismos respectivos, el Tribunal suspenderá el procedimiento administrativo sancionador iniciado y consiguientemente se suspenderá el plazo de prescripción, conforme al artículo 223 del Regla- ADMINISTRATIVO mento modificado.

Por otro lado, si se verifica que el contratista no activó los mecanismos de solución de controversias dentro del plazo establecido para ello, el Tribunal asumirá que la resolución del contrato quedó consentida, aun cuando exista en trámite un procedimiento conciliatorio o arbitral iniciado extemporáneamente".

Así, se excluye analizar la configuración del tipo infractor, menos aún la culpabilidad del imputado. A ello se suma que el Reglamento ha excluido la aplicación de eximentes de responsabilidad en una disposición que es claramente ilegal. ${ }^{15}$

En ese sentido, si un contratista - cuya resolución de contrato ha quedado consentida o se ha confirmado por un tribunal arbitral- es acusado por el Tribunal de Contrataciones del Estado, prácticamente se enfrenta a una crónica de una muerte anunciada, porque está garantizada su sanción.

En suma, si el contratista incumple cualquier obligación del contrato, la entidad le puede penalizar, resolver el contrato, ejecutar la garantía de fiel cumplimiento, demandar daños si la garantía quedó corta y, por si no fuera poco, denunciar ante el Tribunal de Contrataciones del Estado para que se imponga sanción de inhabilitación.

De ahí que sorprende que, en su momento, Mario Linares ${ }^{16}$ haya afirmado que "a la facultad

15. Ramón Huapaya, Néstor Shimabukuro y Oscar Alejos, “Cinco afrentas al régimen sancionador común de la Ley del Procedimiento Administrativo General", Actualidad Jurídica 311 (2019): 22. También: Piero Rojas y Mario Linares, "La contravención de las disposiciones del procedimiento sancionador en materia de contrataciones del estado al régimen común del Texto Único Ordenado de la Ley del Procedimiento Administrativo General", Derecho \& Sociedad 54 (2020): 176.

16. Mario Linares, "El contrato administrativo en el Perú", Revista de Derecho Administrativo 1 (2006): 299. 
de resolver el contrato por incumplimiento en el marco de nuestro ordenamiento de contratos del Estado, no puede tildársele de potestad ni de prerrogativa (...) debido a que no es exorbitante respecto del campo privado". Evidentemente, esta afirmación no tiene sustento hoy en día. Aun cuando pueda discutirse sobre su naturaleza de potestad o prerrogativa, no queda dudas que el régimen es exorbitante respecto de lo que ocurre en los contratos entre privados.

La exageración es innecesaria. Lo que la realidad muestra es suficiente. El contratista queda sin contrato, sin garantía, con menos dinero e inhabilitado para volver a contratar con el Estado. En muchos casos, esa inhabilitación le significa la muerte.

\section{EL DESEQUILIBRIO Y SU FALTA DE JUSTI- FICACIÓN}

No hay novedad en decir que la relación entre la entidad y el contratista público es desequilibrada..$^{7}$ La sola posición de la entidad como parte de la Administración Pública revela que la balanza se inclina a su favor. Recordemos que la Administración no deja de serlo cuando contrata ${ }^{18}$, por lo que se acepta que cuente con determinadas potestades - previstas en la Ley-que le permitan tutelar el interés público subyacente al contrato. ${ }^{19}$

Sin embargo, de ello no se deriva que dicho desequilibrio pueda ser tan acentuado, mucho menos que puedan establecerse reglas sin justificación alguna. Precisamente creemos que este es un caso en el cual no existe mayor justificación para que la balanza se encuentre tan inclinada a favor de la Administración.
Un primer punto que debe tomarse en cuenta es que la elección de la forma contractual para alcanzar el interés público implica que la Administración está privilegiando la colaboración, antes que la imposición. Nos explicamos.

Meilán Gil ${ }^{20}$ habla sobre la instrumentalidad de las categorías para sostener que la Administración elige entre acto y contrato con una dosis de oportunismo. En ese sentido, en algunos casos podría actuar por medio de actos administrativos, cuando quiere imponerse unilateralmente -por ejemplo, en una expropiación-; mientras que, en otros casos, buscará los mismos objetivos mediante un contrato, privilegiando la colaboración antes que la imposición.

Si esta es la lógica que inspira las relaciones contractuales de la Administración, pierde sentido que las normas hayan establecido un régimen tan diferenciado en perjuicio del contratista. En efecto, con estas reglas no sólo se desincentiva la participación de más postores, sino que además se les niega la condición de colaboradores de la Administración.

Un segundo punto trae a colación los conceptos de exceso de punición y razonabilidad. La lógica detrás del principio de razonabilidad es que la Administración utilice los medios más idóneos y proporcionales, pero menos gravosos para lograr sus objetivos - artículo IV de la Ley de Procedimiento Administrativo General- - . Si el objetivo es desincentivar el incumplimiento, queda claro que no son necesarias tantas armas - penalidades, garantías, resolución, sanción, etc.-.

Por ello, desde fuera, se ha criticado la legislación peruana por la existencia de potestad

17. Oscar Alejos, "Convenios arbitrales desequilibrados en los contratos públicos bajo la Ley de Contrataciones del Estado", Derecho PUCP 28, (2019): 349.

18. Ramón Huapaya, "Concepto, especies y criterios del contrato público" en Estudios de Derecho Administrativo. El Derecho Administrativo Iberoamericano. Innovación y reforma. Libro Homenaje al Profesor Juan Carlos Cassagne, (Lima: Gaceta Jurídica, 2018), 624.

19. José Luis Meilán Gil, "Para una reconstrucción dogmática de los contratos administrativos", Anuario da Facultade de Dereito da Universidade da Coruña 8 (2004): 518.

20. Ibid 508 . 
sancionadora en estos casos. ${ }^{21}$ Según este autor, el régimen de penalidades sería suficiente para desincentivar el incumplimiento, además que la entidad recibiría una suerte de resarcimiento. En ese sentido, mantener un régimen sancionador en estos casos sería realmente un exceso que, además, termina por desconocer que la potestad sancionadora - como la penal- debe ser considerada una herramienta subsidiaria.

Un tercer punto es que este régimen nos lleva a un resultado que termina por afectar el interés público que se quiere tutelar. Íñigo Sanz ${ }^{22}$ habla de la sanción de inhabilitación como una "autoprohibición para contratar" $y$, por ende, de una sanción absurda. La razón es que, en muchos casos, al inhabilitar a tantos proveedores —cuando se podría recurrir a otras medidas suficientes como las penalidades contractuales-, el Estado termina quedándose sin oferta. Si bien ello es un tema menor en mercados competitivos - por ejemplo, útiles de escritorio, alimentos, computadoras-, sí se convierte en un serio problema cuando estamos en mercados con poca oferta - por ejemplo, tecnología, telefonía, medicinas-.

Lo expuesto nos permite concluir que no existen razones para este desequilibrio en las normas que regulan la resolución del contrato por incumplimiento. El desbalance a favor de la Administración no solo carece de justificación, sino que puede terminar por vulnerar el mismo interés público que supuestamente protege.

\section{MÁS ALLÁ DE LA REFORMA: CÓMO CAM- BIAR LAS COSAS SIN CAMBIAR LA LEY}

Frente a una mala ley, es buena una interpretación razonable. Esta es la premisa de la que partimos para intentar superar el desequilibrio que hemos descrito y criticado en el apartado anterior. Lo ideal sería, claro está, un cambio normativo; sin embargo, mientras ello no ocu- rra, podemos utilizar como guía una interpretación adecuada de la norma.

Dicha interpretación debe partir de distintos sujetos. Así, se requiere una interpretación de la entidad para determinar cuándo debe resolver y cuándo corresponde ejecutar una garan- ADMIIIITRATIVO tía. Asimismo, se requiere una interpretación de los árbitros para determinar cuándo el incumplimiento amerita una resolución, y es necesario decirlo, no bajo reglas civiles, ni bajo una interpretación desequilibrada en base a la literalidad del Reglamento; por el contrario, se requiere una interpretación equitativa, paritaria, que parta del concepto y finalidad del contrato público, y no aplicar en forma desequilibrada la resolución contractual. Finalmente, se requiere también una interpretación del Tribunal de Contrataciones del Estado que, valorando adecuadamente los hechos, decida si corresponde aplicar una sanción en cada caso concreto. Vamos en orden.

Con relación al incumplimiento que habilita la resolución, hemos señalado que el Reglamento establece una diferencia literal que permitiría a la entidad resolver el contrato por el incumplimiento de cualquier obligación, mientras que el contratista sólo podría resolver por el incumplimiento de una obligación esencial. Así se desprende del artículo 164 del Reglamento.

Sin embargo, lo cierto es que la norma no establece expresamente que la entidad pueda resolver frente a "cualquier incumplimiento", simplemente omite el término "esencial". Surge entonces la pregunta: ¿de dicha omisión debe necesariamente deducirse que la entidad puede resolver por cualquier incumplimiento? Consideramos que no, de ninguna manera. La interpretación literal de un contrato público resiente a su esencia y finalidad.

El silencio de la norma puede interpretarse de múltiples formas. Una de ellas es la que viene

21. Sanz, "Propuesta para una mejora del régimen sancionador en materia de contratos público", 133.

22. Ibid 138. 
reinando en los árbitros, probablemente porque es la que se desprende literalmente del texto de la norma.

Aquí se propone una lectura distinta de la norma, más razonable y sustentada en el principio de buena fe, el cual sirve de guía para interpretar los alcances de todas las prerrogativas de la Administración. ${ }^{23}$ Para ello, seguimos lo señalado por Cassagne ${ }^{24}$, para quien la buena fe reclama lealtad de la contraparte, lealtad que impide resolver el contrato - es decir, recurrir al remedio más drástico- por cualquier incumplimiento que resulte de escasa trascendencia.

En ese sentido, una interpretación acorde con la buena fe sería considerar que, tanto contratista como entidad, están limitados a resolver el contrato solo cuando medie el incumplimiento de una obligación esencial. Queda descartada la posibilidad de resolver por cualquier incumplimiento; si se hace, se vulnera la buena fe, con las consecuencias que de ello se derivan.

La misma lógica de razonabilidad se impone al momento de decidir si se ejecuta una garantía o no, así como qué debe hacerse en caso de desproporción entre el monto ejecutado y los daños efectivamente conculcados. Aquí la razonabilidad exige que la entidad —si bien constreñida legalmente a ejecutar por el tododevuelva aquel monto que resulte excesivo en comparación con el daño causado. Ese mismo análisis se exige de los árbitros que tengan que lidiar con una controversia de este tipo.

Finalmente, en lo que se refiere al régimen sancionador, dos medidas pueden ser tomadas en cuenta por el Tribunal. La primera consiste en reconocer que nos apartamos del principio de oficialidad y pasamos a uno de oportunidad para el inicio de procedimientos sancionadores $^{25}$; es decir, el Tribunal debe reconocer que no está obligado a iniciar procedimiento, sino que puede hacerlo de considerarlo conveniente. En otras palabras, el Tribunal debería ser capaz de no sancionar si determina que el interés público ya ha sido bastante cautelado - con tantas penalidades, garantías, indemnizaciones, etcétera-.

La segunda medida pasa por comprender que el procedimiento sancionador en estos casos no debe ser automático, sino que es necesario que el Tribunal evalúe adecuadamente los casos que son sometidos a su conocimiento. En dicha evaluación, el Tribunal debe partir de la premisa que la falta de cuestionamiento de una resolución en arbitraje no implica consentimiento. Así lo sostuvo la Corte Suprema en la sentencia de Casación N 15205-2016-Lima, publicada el 31 de julio de 2019 en el Diario Oficial El Peruano. En dicha sentencia, la Corte Suprema confirmó la nulidad de una sanción impuesta por el Tribunal, al constatar que éste no había analizado la legalidad de la resolución contractual; de esa forma, se descartó que el contratista hubiera consentido una resolución sólo por no haber acudido al arbitraje.

Lo expuesto permite comprender que los casos de infracciones por supuestamente dar lugar a la resolución del contrato no son tan fáciles como ha pretendido ver el Tribunal en los últimos años. Es imprescindible, entonces, romper viejos mitos, y empezar a analizar cada caso con sus particularidades.

23. Véase: Ramón Huapaya, "Una propuesta de formulación de principios jurídicos de la fase de ejecución de los contratos públicos de concesión de servicios públicos y obras públicas de infraestructura (con especial referencia al marco jurídico de promoción de la Inversión Privada en el Perú)", Ius et Veritas 46 (2013): 318; y, Juan Carlos Morón, La contratación estatal, (Lima: Gaceta Jurídica, 2016), 199.

24. Juan Carlos Cassagne, El contrato administrativo, Tercera edición, (Buenos Aires: AbeledoPerrot, 2009$), 100$.

25. Véase: Sanz, “Propuesta para una mejora del régimen sancionador en materia de contratos público”, 144; y, Óscar Alejos, "Los olvidados principios de razonabilidad y proporcionalidad. A propósito del caso ACIP contra La Rosa Náutica", Diálogo con la Jurisprudencia 255 (2019): 78. 


\section{REFLEXIONES CONCLUSIVAS}

Como hemos señalado a lo largo de este artículo, es normal que existan diferencias entre entidad y contratista. La propia naturaleza de la Administración Pública y su deber de velar por el interés público así lo exigen. Por eso la Ley le concede distintas prerrogativas - modificación del contrato, intervención de la obra, etcétera- que forman un régimen exorbitante a su favor. ${ }^{26}$

En la mayoría de los casos dichas prerrogativas tienen una clara justificación en el interés público. Un ejemplo claro es la aprobación de adicionales; si una obra requiere de una prestación adicional para cumplir con su finalidad, tiene pleno sentido que se apruebe el adicional.

Pero en otros casos, la diferencia entre contratista y entidad pierde sentido, y no existe interés público que la justifique. Sucede así en el régimen del incumplimiento, en donde la balanza se inclina a favor de la entidad. Como hemos visto a lo largo de este artículo, el contratista no sólo queda en una posición desventajosa, sino que además es severamente vapuleado hasta prácticamente morir como contratista del Estado.

Sin duda, estos excesos reclaman un cambio legislativo. Lamentablemente esos cambios tardan mucho en llegar o no llegan nunca, quedando la solución - temporal, parcial y subóptima - en manos de los que aplican el derecho - funcionarios, litigantes, árbitros-. Así, hemos presentado algunas posibles soluciones que tienen en común una interpretación de las normas basada en el principio de razonabili-ADMINISTRATIVO dad.

Sin perjuicio de ello, nos parece que este tema invita a la reflexión respecto de qué esquema de contratación pública queremos. Es cierto que la Administración no deja de serlo cuando contrata, pero también es cierto que recurre al contrato en lugar del acto, precisamente porque prefiere un esquema de colaboración, antes que uno de imposición.

Si partimos de esta premisa, entonces no es difícil comprender que la Administración debería adoptar una posición más colaborativa en la ejecución de sus contratos, privilegiando los acuerdos, pactos y transacciones, antes que las imposiciones y los litigios. El contratista no debe ser visto como enemigo; debe ser visto y tratado como un colaborador, como alguien necesario para que la Administración cumpla con sus finalidades de interés público, en una lógica de colaboración, beneficio conjunto y conmutatividad, como lo expresa calificada doctrina. ${ }^{27}$

26. Véase: Cassagne, El contrato administrativo, 26; y. José Luis Meilán Gil, “Una concepción iusadministrativista de los contratos públicos", Derecho PUCP 66 (2011): 242.

27. Pedro Fernández Sánchez, Direito da Contratação Pública. I, Primera edución, (Lisboa: AAFDL Editora, 2020), 17 